\title{
Enhancing patient well-being: advocacy or negotiation?
}

\author{
Ann W Bird St Mary's Hospital, London
}

\section{Author's abstract}

The United Kingdom Central Council for Nursing, Midwifery and Health Visitors (UKCC) document, Exercising Accountability, states that the role of patient's advocate is an essential aspect of good professional nursing practice (1). The author examines the case for and against the nurse being the best person to act as advocate, and critically evaluates the criteria of advocacy. The problematic moral issues arising are discussed, and a case made for negotiation between the members of the multidisciplinary team and the patient/client (or a significant person to the patient) in order to promote the well-being of the patient and to minimise suffering. She concludes that the health care professional's (including the nurse's) role is to help people to assert control over the factors which affect their lives, that is empowerment, rather than advocacy.

In the recent nursing professional literature the nurse has been hailed as 'the patient's advocate'. The statutory body for nursing, the UKCC, in its document, Exercising Accountability envisages 'the role of patient or client advocate as an integral, and essential aspect of good professional practice' (1). However, due to its adversarial nature, advocacy has also been accused of promoting professional discord, of being both paternalistic and an unwarranted interference in the autonomy of another.

The notion of advocacy has its roots in the legal profession, where an expert, a lawyer, is called in to defend the interests of a person in a dispute. (Latin 'Advocare' - to call in.) It involves pleading for the cause of one's client: the intercession for, or the defence of, someone. It means defending someone, even if they are wrong, and are known to be wrong.

Curtin, Abrams and Gadow $(2,3,4)$ have described the nurse's role in advocacy as one of assisting patient autonomy in decision-making. Abrams (3); the advocate as counsellor or lay therapist; Curtin (2) as the patient's rights advocate; Abrams (3) as representation of the unconscious or incompetent patient, and Curtin (2) as advocacy

\section{Key words}

Decision-making; advocacy; negotiation; empowerment. being essentially a role of disinterest or neutrality. Gadow (4) has described it also as spiritual advocacy, the nurse assisting the patient to find a $\omega$ unique meaning in suffering.

The case for the nurse as advocate in health care is based on two important considerations. Firstly, the unequal power relationships that exist within the $\vec{c}$ health care system itself, that is the formidable might $\$$ of the medical profession, the general managers and $\underset{\mathbb{D}}{\mathbb{D}}$ budget-holders on the one side and the ill, $\overline{0}$ vulnerable person on the other. And secondly, that $\stackrel{\mathbb{Q}}{-}$ as persons are an integration of mind and body, and $\overrightarrow{0}$ because the nursing profession tends to regard each patient as an individual with a mind that requires much attention as the body, whereas the medica profession (certainly the hospital service) practise 'reductionist care' due to their high specialism as ear, nose and throat surgeons, or orthopaedic $\stackrel{\circ}{\varnothing}$ surgeons, or chest surgeons, or psychiatrists, it is the nurse that should take on the role as patient's $\overrightarrow{\overrightarrow{0}}$ advocate.

The argument in support of nurses can be elaborated by explaining that not only do nurses attend patients when distress is immediate, but they attend them for sustained periods, often providing those intimate details of physical and emotional care that lead to deepened knowledge of a person as a distinct and unique human being. Because unequal doctor-patient relationships exist, it is incumbent on the nurse to take on the responsibilities and challenge of being the patient's advocate, despite the $\frac{}{0}$ conflict that may arise as a result within the multidisciplinary health care team.

The case against the nurse as advocate runs on the following lines. Stating that patients or clients need $\mathrm{N}$ 'advocates' means that the whole fabric of health $\omega$ care decision-making is unsound and George Bernard Shaw's claim 'all professions are a읃 conspiracy against the "laity", is true. Secondly, advocacy, takes power away from the patient. Why? should the patient not be able to speak for him or her self? The case of the nurse as advocate, may be $\frac{\vec{D}}{\mathrm{P}}$

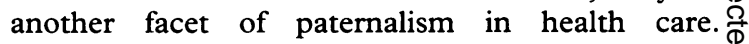
Furthermore, the UKCC document, Exercising $\cong$ Accountability, mentioned previously, admits that all the other health care professionals, not only the 
nurse, can also be the patient's advocate (1). If each faction claimed to speak for the patient, the presence of so many 'advocates' could be a recipe for disaster. This would only increase interprofessional rivalry and discord, possibly jeopardising the well-being of the patient instead of enhancing it.

The nurse as a member of the multi-disciplinary health care team, owes trust and loyalty to the other members of the health care team, as well as loyalty to the patient. It could be very difficult to balance these loyalties in an adversarial environment rather than one of mutual care and support.

Porter (5), using sociological arguments, explains that as nurses are part of the power structure of health care which defines who is sick and how they should be treated, the best the nurse can offer is 'benign paternalism rather than advocacy'. If paternalism has its roots in coercion, benign or otherwise, then Porter's alternative must also be rejected. Porter goes on to suggest that if an advocate is needed, perhaps a kindly, wise friend who understands the patient's aspirations and values, someone who is trusted by the patient, may make a better advocate than a member of the professional health care team, when an 'advocate' is actually needed, for example when the patient is unable to exercise his or her autonomy because he or she is unconscious, mentally ill, or mentally handicapped. The position I would wish to take is that if the multi-disciplinary team exercise their responsibility and accountability in acting in the best interests of patients in carrying out their duty to care and to avoid harm - then 'advocates' are unnecessary.

\section{Criteria of advocacy}

In order to assist in clarifying this debate, it is essential to examine the criteria of advocacy $(6,7)$. Firstly, the nurse is obliged to give unbiased information to the patient. Secondly, the nurse must accept the decisions made by the patient on the basis of the information given. Thirdly, the nurse must defend the consequences of the decision against all-comers. Fourthly, the nurse should submerge her/his own views and adopt the principle of 'disinterestedness', 'which means that the nurse's motivation is the pursuit of impersonal values such as the advancement of science and the welfare of the clients, so that the interests of the clients are always impartially put above the nurse's own interests'. Fifthly, the nurse should adopt the principle of universalism which Talcott Parsons has described as emotional neutrality towards the client, that is, whatever race, sex, colour, creed, politics, age or social status.

Taking these five criteria of advocacy, as expanded by Kohnke (7), we can agree that nurses and other health care personnel should give the patient all the relevant up-to-date information required to make an informed choice. For example, consider a situation where a woman has been told that she has cancer of the breast. Several options are available. The first one is to have the lump removed only (wedge resection of the breast) and the package of treatment includes cytotoxic (chemo)therapy, for example three doses if there is no lymph-gland involvement or six doses if there is lymph-gland involvement. This could be followed by a programme of radiotherapy as an out-patient. Because of the chemotherapy, the patient's hair will fall out, but a wig of the patient's choice will be made up beforehand. However, following completion of the cytotoxic therapy, the patient's hair will grow again, often more thickly than before. Nausea and vomiting occur during the cytotoxic therapy, but it wears off on completion. A breast augmentation operation (implant to restore the full shape of the breast) can be performed later if the patient desires this.

The patient should consider whether she would like her partner to be included in the decisionmaking because of psychological reactions which may affect their relationship. The patient may opt to have a mastectomy (removal of the whole breast and lymph nodes). Or the patient could opt for mastectomy, followed by radiotherapy. Or she could choose that following mastectomy, she will take hormones which will decrease female-gland-cell $\Phi$ development. This latter treatment should only be undertaken by those women who do not wish to have any more children. Or one could take the drug Tamoxifen, which is effective in dealing with the breast cancer, but which it is also thought, could cause some serious side-effects elsewhere in the body. All the possible options and possible consequences need to be discussed thoroughly, otherwise an informed choice will not be possible. The patient will be plumping for something in the dark. However, there is always the danger that some patients may be put off by hearing details of what may ensue. The nurse needs to be sensitive to this, but informed consent is necessary.

However, Kohnke's dictum $(6,7)$ that advocacy means that the nurse must accept the decisions made by the patient on the basis of the information given, does not apply in all cases and her exhortation that the patient's decision must be defended against allcomers, may be detrimental to the ultimate wellbeing of the patient, in some instances, for the following reasons.

The patient may have come with preconceived ideas, for example, having heard 'old wives' tales', or believing that a particular operation worked for her next-door neighbour or great aunt Matilda, therefore it is right for her. These notions are often so deeply ingrained that all the information to the contrary may be unable to change them.

The patient may also want something that is not in her best interest, for instance, to commit suicide 
or to take her own discharge from hospital when this means that there is a great possibility of her collapsing before reaching the front door of the hospital.

Furthermore, the patient may be so ill as to be encumbered in her decision-making for her best interest, due to a severe pyrexia or to mental depression which is part of the disease symptoms themselves. Whereas, if the patient were not so seriously ill, she would choose differently. The patient may be unaware that the depression, for instance, will lift as the disease is cured. Some patients even after being told about this, refuse to believe it. Patients may also be unsure of what they actually want and while attempting to weigh each option available, frequently appear to be favouring one option today and another tomorrow. Patients may change their minds completely.

\section{Moral code}

Getting informed consent is a good thing but the problems inherent in this complex arena should be borne in mind. Taking Kohnke's assertion that the nurse advocate should defend the patient's decision against all costs, is problematic (7). The patient's choice may infringe the moral code of the nurse, for example a paranoid schizophrenic patient decides to kill the patient in the next bed. Or, the patient, who has false impressions about the efficacy of blood substitutes, refuses a blood transfusion following coercion by her Jehovah's Witness mother. The latter patient subsequently died.

Kohnke asserts that the nurse should submerge her own views and adopt Talcott Parsons's principles of 'disinterestedness' and 'universalism', and explains that being disinterested means that the professional's motivation is the pursuit of impersonal values such as 'the advancement of science and the welfare of clients' (7). Thus she must at all times impartially put the interests of her clients above her own. Putting the patient first is to be commended. However, the advancement of science may be a good thing for science and the scientists but it may cause unnecessary pain and suffering to the patient. Utilitarian considerations such as using the patient in a medical research programme in order to help other patients in the future with little or no benefit for this patient, is problematic. The gains for the patient, if any, may not warrant the suffering entailed. The advancement of science may be counter-productive to the welfare of this particular patient. There appears to be an underlying assumption here that altruism towards patients, on the part of nurses is necessary. Putting the client's interest at all times above her own, makes altruism mandatory for the nurse advocate. We can agree that the nurse puts the interests of her patients above her own, but in certain instances, such as in nursing violent patients, prudence may be more moral for the nurse. As the issues raised here are immense, they will be addressed in a separate paper.

The premise of pursuing impersonal values also begs examination. People value this rather than that. $\frac{\vec{s}}{2}$ We differ in our values but respect others' values. The professional should be able to say: 'Well, I do 듬 not agree with abortion, but I see that in your case if $\frac{\overline{\bar{c}}}{\overline{\frac{1}{3}}}$ you proceed with this pregnancy it could damage $\mathbb{D}$ your health, your family's well-being and the future well-being of the child because of your poor social ${ }^{\text {s }}$ conditions'. One cannot have an impersonal value $\vec{\circ}$ such as 'the preservation of life at all cost' in a $\overrightarrow{\vec{\omega}}$ vacuum. All issues are situation and people specific. $\mathscr{\sigma}$

Kohnke asserts that 'the professional should $\overline{3}$ adopt an emotional neutrality toward the client, that $\Phi$ is, whatever race, sex, colour, creed, politics, age, $\stackrel{O}{0}$ social status' (7). If being unbiased is what Kohnke $\omega$ means, then we can go along with it. What is $\vec{N}$ required is for the nurse and all health care ${ }_{0}$ professionals, however, to take into consideration the cultural beliefs of our patients and the meanings $\vec{c}$ inherent in their experiences for them. Even for $\frac{\mathbb{D}}{O}$ mentally handicapped, mentally ill or unconscious $\overrightarrow{\mathbb{D}}$ patients, the multi-disciplinary health care team, if $\frac{3}{\sigma}$ exercising the responsibility and accountability $\frac{\Phi}{-}$ central to its role, ought to be able to decide what is $\vec{\bullet}$ in the clients'/patients' best interests, withogi recourse to advocates. Loved ones, or even respectable citizen, can be asked to contribute the opinions before decisions are made. However, if $\cdot \mathrm{a}$ nurse or any other member of the health care team or any relative decides that the best interests of the $\frac{0}{\Phi}$ patient are not being served by the professionals, $\cong$ then to challenge this is the moral thing to $\overrightarrow{\overrightarrow{0}}$ do. Empowerment to act against injustice or 3 incompetence is what is needed, rather than 'advocacy' with its unnecessary and perhaps immoral baggage.

\section{Procedures and policy}

It is part of the duty of all health care professionals, including the nurse, to speak out if, with his/her own considerable knowledge, skill and experience, it is evident that the locum house officer has failed to $\frac{7}{0}$ identify, for example, a patient in sickle cell crisis, or if the consultant has misunderstood the patient's $N$ position, or an incorrect drug dose has been $N$ prescribed. This duty exists quite independently of any notions of 'advocacy'. Procedures and policy should be explicit in order to protect all professionals, other staff members, or members of the public who are aware of practices which are contrary to the patient's welfare, for example if a ward full of ${ }^{-}$ patients is being given chlorpromazine in order to make them more compliant.

Using our emotions and our rationality may be $\frac{\rho}{\mathrm{C}}$ much more effective as a motivational factor in $\underline{0}$ enhancing well-being, reversing injustices and making resources available for those that are most deprived 
than cool objectivity alone. Our emotions are frequently the catalyst which instigates and maintains improved conditions. An emotional neutrality may encourage the perpetuation of the status quo. Of course, getting too emotional may be counterproductive. But as Aristotle (8) maintained, there is an optimum amount which is best for well-being. Our emotions, if used correctly, can themselves be rational.

Many decisions to be made in health care are not clear-cut, for example should a 60 -year-old mentally handicapped person, who is unable to give consent, have a total hip replacement or a 45-year-old woman have surgery or cytotoxic or hormone therapy for breast cancer, or an 80-year-old bronchitic woman who refuses food have her wishes respected?

One must question whether advocacy is a necessary part of the nursing or any health care professional's role. In health care which involves people with different values and cultural and racial roots, negotiation about values is an important element in moral decision-making for personal wellbeing. This negotiation must necessarily include the patient as far as is possible. If that is not possible it should involve a person of significance to him, and of course it should involve the multi-disciplinary health care team. Such negotiation will often include compromise. In this context, I am using the word 'compromise' to mean a moral settlement of differences by mutual concession for the good of the patient, while not jeopardising the professional integrity of the health care personnel. Throughout this paper, I shall adhere to this meaning of compromise. At no time do I use 'compromise' in the sense of 'to expose to risk or injury, suspicion, censure or scandal'. Indeed it is just this that must be avoided at all costs in health care: the main aim of health care being the promotion of personal wellbeing.

\section{Tensions and conflict}

There may be tensions and conflict within the patient's own inclinations and judgement. Sufficient time is required to sift information, to weigh the merits of options and their consequences. What may appear the best decision about surgery to the patient, may not be so, for the surgeon, unbeknowst to the patient, may be more skilled at doing another sort of operation. The patients' relatives, who feel they know him, may recommend another course of action. How can these differences in autonomy and perception be reconciled to ensure the well-being of the patient? It is only by meeting together and discussing needs, desires, fears and uncertainties that the best way forward can be determined. The patient should be able to question the health care professionals and ask for clarification in an environment of mutual trust and support. The conventional ward round is not a suitable place for these discussions and negotiations to occur. Firstly, ward rounds are carried out in public wards, and secondly the patient, faced by the whole medical entourage, may feel intimidated and powerless and end up saying 'Yes, doctor' to whatever suggestions are made. The venue needs to be chosen carefully in order to help the patient to be comfortable and feel supported so that he/she can say what he/she actually feels. At the moment, all information is given in a fragmented way. The doctor sees the patient; the nurse and physiotherapist may not know what the surgeon has said to the patient, or what the patient has said to the surgeon.

A supportive environment away from the bustle of the ward, a relaxed and quiet place where the patient and significant others (with the permission of the patient) can meet members of the multidisciplinary team, will enhance negotiation. The nurse needs to ensure that the patient has had all the relevant information in advance so that the patient has time to reflect and prepare questions to ask. Relevant practitioners, such as the community service nurse may need to be present. The nurse should help the patient to express his views, if he appears hesitant. It is essential for the nurse to demonstrate loyalty to the patient and to the health care team during the clarification of important issues. The overriding principle of the negotiation is to enhance the patient's well-being and to minimise suffering.

Patients have hopes, aspirations and duties to people they love and are loved by. Health care professionals may be unaware of these, but it is our duty to ascertain these as part of the decisionmaking process. Competing views need to be aired and critically evaluated before negotiation can begin. The patient and the health care team should then consider what values cannot be compromised and what can. Haydon (9) has pointed out that both an uncompromising stand on principles, and a willingness to compromise, can be admired. Which position occurs will depend on the specific situation, the various moral issues coming into conflict in varying degrees, and the availability of resources and skills. What must be avoided at all costs is the taking of decisions by one professional only in nonemergency situations, so that the patient's pleas go unheard and unacknowledged, and the use of the patient as a vehicle for promoting personal or sectional interests.

In conclusion, the role of the nurse as patient's advocate is untenable. The way forward in enhancing patient well-being is through negotiation and perhaps compromise. The nurse's role is rather to help people to assert control over the factors which affect their lives: her role is the complex one of empowerment, rather than advocacy.

Discussion, negotiation and informed choice are necessary in health care for moral decision-making. Truth and morality often lie in the grey areas between the extremes which most people choose to see. 
Ann W Bird, MA Lond, BEd (Hons), Sister Tutor's Dip, RCNT, RGN, is senior education manager and head of ethics unit, North West London College of Nursing and Midwifery, Praed Street, London.

\section{References}

(1) UKCC. Exercising accountability [2nd ed]. London: UKCC, 1989: 12-13.

(2) Curtin L L. The nurse as advocate: a cantankerous critique. Nursing management 1983; 114: 9-10.

(3) Abrams N. A contrary view of the nurse as patient advocate. Nursing forum 1978; 17: 258-259.
(4) Gadow S. Existential advocacy: philosophical foundation of nursing. In: Spicker S F, Gaddow S, eds. Nursing images and ideals: opening dialogue with the humanities. New York: Springer Publishing Company, 1980.

(5) Porter S. Siding with the system. Nursing times 1988; 84: $30-31$.

(6) Kohnke M F. Advocacy: risk and reality. London: Mosby, 1980.

(7) Kohnke M F. Advocacy: What is it? Nursing and health care $1982 ; 3,6: 314-318$.

(8) Aristotle. Nicomachean ethics. Bk II: ch VI.

(9) Haydon G. Compromise. Paper delivered at the Research Seminar, Philosophy department, Institute of Education, University of London, 10 Jan 1990.

\section{News and notes}

\section{Ethical Issues in Health Care}

A conference for all health professionals, Ethical Issues in Health Care, will be held at the University of Brighton on $21 \mathrm{st}$ and 22nd September this year.

The conference is designed to encourage dialogue on ethical issues in health care between health care professionals and educators from the fields of nursing, midwifery, medicine, physiotherapy and other professions allied to medicine.

Workshops will include: Ethical issues and communication; Teaching ethics to health professionals; Rationing of health care, and Patient/client choice.

For further details please contact: Jackie Lawrence: tel: 0892823535 ext 3131; fax: 0892823137.

\section{Submitting manuscripts for publication}

Papers submitted for publication should be sent in quadruplicate to: The Editor, Fournal of Medical Ethics, c/o Imperial College of Science, Technology and Medicine, 14 Prince's Gardens, London SW7 1NA. The journal considers papers only if they are not under consideration by any other journal at the same time. Rejected manuscripts are not returned. Papers should be in double-spaced typewriting on one side of the paper only. The preferred maximum length of papers is 3,500 words - absolute maximum 5,500 (including references). A total word count (including references) is requested. On a separate sheet some brief biographical details should be supplied, including the title of the author's present post, degrees and/or professional qualifications (if any), and any other relevant information.

Two copies of the journal will be sent to authors free of charge after their papers are published. Offprints of individual papers may be bought from fournal of Medical Ethics, BMA House, Tavistock Square, London WC1H 9JR.

In March 1981 the $f M E$ adopted a simplified 'Vancouver style' for references: details are given in various issues, including December 1990. They are also available from the editorial office. The full text of the 'Vancouver Agreement' was published in the British Medical fournal in 1988; volume 296; 401-405. As the 'Vancouver style' is incompatible with the long established style of references for legal articles, lawyers should use their own standard style, but try to facilitate reference by others. The journal is multidisciplinary and papers should be in clear jargonfree English, accessible to any intelligent reader. 